\title{
A Conformational Switch to $\beta$-sheet Structure in Cytochrome c Leads to Heme Exposure; Implications for Cardiolipin Peroxidation and Apoptosis
}

\author{
Gurusamy Balakrishnan, Ying Hu, Oyeyemi F. Oyerinde, Jia Su, John T. Groves, and Thomas \\ G. Spiro \\ Department of Chemistry, Princeton University, Princeton, New Jersey 08544.
}

\begin{abstract}
Ultraviolet resonance Raman spectroscopy reveals that, when heated at $\mathrm{pH} 3$, a substantial fraction (30\%) of cytochrome c converts to a $\beta$-sheet structure, at the expense of turns and helices. $\beta$-sheet formation is rapid, exhibiting a $2 \mu$ s rise time, following a temperature jump. It is proposed that a short $\beta$-sheet segment, comprised of residues 37-39 and 58-61 extends itself into the large 37-61 loop, when the latter is destabilized by protonation of $\mathrm{H} 27$, which forms an anchoring $\mathrm{H}$-bond to loop residue $\mathrm{P} 44$. This conformation change ruptures the Met80-Fe bond, as revealed by changes in ligation-sensitive heme-resonant Raman bands. It also induces peroxidase activity with the same temperature profile. This process is suggested to model the apoptotic peroxidation of cardiolipin by cytochrome c.
\end{abstract}

\begin{abstract}
We report resonance Raman (RR) spectroscopic evidence for a hitherto unrecognized conformational transition to $\beta$-sheet structure in cytochrome $\mathrm{c}$ (cyt $\mathrm{c}$ ), which may have important functional consequences.
\end{abstract}

In addition to its electron-transfer activity in mitochondria, cyt c plays a key role in apoptosis, 1 and partial unfolding seems to be a critical element in the mechanism. Jemmerson et al. have observed that, in association with lipid vesicles, cyt $\mathrm{c}$ binds an antibody that recognizes an unfolded region around residue Pro44, and that the same response is seen in apoptotic cells. ${ }^{2}$ Belikova et al. report that binding to cardiolipin induces peroxidase activity in cyt c, producing cardiolipin hydroperoxides that are required for release of pro-apoptotic factors. ${ }^{3}$ It seems likely that this activity is triggered by changes in heme ligation when cyt c interacts with lipids. ${ }^{4}$ In addition to cardiolipin, ${ }^{5}$ oleic acid 6 has been observed to destabilize the cyt $\mathrm{c}$ fold; the oleic acid effect can be partially reversed by ATP, a component of the apoptosome. ${ }^{6}$

We find that heating cyt $\mathrm{c}$ under destabilizing conditions ( $\mathrm{pH} 3$ ) not only unfolds a significant fraction of the protein, but converts it to a $\beta$-sheet structure. This conversion is reversible unless the concentration exceeds $50 \mu \mathrm{M}$, when cyt c precipitates upon heating. Moreover $\beta$-sheet formation is remarkably fast, occurring on the microsecond time scale. This structural change is associated with rupture of the Fe-S bond (heme-Met80), and induction of peroxidase activity.

The evidence for $\beta$-sheet formation comes from UVRR spectroscopy. Excitation at $197 \mathrm{~nm}$ produces optimal enhancement of amide vibrational modes, whose frequencies and intensities are diagnostic of secondary structure. ${ }^{7 a}$ UVRR signatures have been extracted from a suite of structurally characterized proteins, allowing quantitation of secondary structure. ${ }^{7 b}$ Figure 1

spiro@princeton.edu. 
shows the result of applying this procedure (supporting info, S1) to UVRR spectra of equine $\mathrm{Fe}^{\mathrm{III}}$ cyt $\mathrm{c}$ at $\mathrm{pH} 3$. At $20^{\circ} \mathrm{C}$, the secondary structure is $18 \% \beta$-turn, $40 \% \alpha$-helix, and $42 \%$ unordered structure. This composition is consistent with the crystal structure of native cyt $c^{8}$. As the temperature rises, all three of these elements diminish, while the $\beta$-sheet content rises from near-zero to $30 \%$. The far-UV circular dichroism temperature profile (supporting info, S2), shows loss of $\alpha$-helix at about the same temperature as the UVRR analysis; however CD does not readily distinguish unordered structure from $\beta$-sheet. In contrast, the UVRR signatures are distinctive, especially in the amide III and S region, which is highly sensitive to conformation, as can be seen in the inset to Figure 1.

Cyt $\mathrm{c}$ is known to form $\beta$-sheet aggregates, e.g. when heated in the presence of denaturant, ${ }^{9}$ and intermolecular association has been detected in the course of cyt c folding studies. 10 However, reversible $\beta$-sheet formation has not previously been reported. To investigate the rate of this process, we applied a laser temperature jump, using a recently described $1 \mathrm{kHz}$ OPO solid state laser, timed to our UVRR probe laser, ${ }^{11 \mathrm{la}}$ and obtained a $2.2 \mu$ s time constant for $\beta$-sheet formation (supporting info, S3). Thus the structural conversion is rapid, on the same time scale as, for example, the melting of helices in apomyoglobin. ${ }^{11 \mathrm{~b}}$ Aggregation to intermolecular $\beta$-sheets is a much slower process. ${ }^{11 \mathrm{c}}$

What is the nature of intramolecular $\beta$-sheet formation in cyt $\mathrm{c}$ ? Figure 2 shows the protein fold. The left-most segment is a large $\Omega$ loop $^{12}$ (40s $\Omega$ loop), containing residues 40-57 (orange), which has been identified by Englander and coworkers ${ }^{13}$ as the least stable of the cyt c 'foldons', structural elements found via NMR to unfold as cooperative units. At the ends of the 40s $\Omega$ loop is a 'neck' of residues, 37-39 and 58-61 (colored yellow in Figure 2), which are arranged in a short anti-parallel $\beta$-sheet. The $40 \mathrm{~s} \Omega$ loop is labilized at low $\mathrm{pH}$, probably because anchoring H-bonds, His $26 \cdots$ Pro $44^{14}$ and Thr $49 \cdots$ heme propionate, are disrupted by protonation. 13

Our hypothesis is that upon heating at $\mathrm{pH} 3$, the 37-39/58-61 $\beta$-sheet neck extends itself into the $40 \mathrm{~s} \Omega$ loop, forming additional $\beta$-sheet at the expense of the three $\beta$-turns and the short $50 \mathrm{~s}$ helix contained in the loop. The pre-existence of the $\beta$-sheet neck can explain the fast rate of the process. To account for the more extensive helix loss at higher temperature (Figure 1), we suggest that the sheet structure continues to grow at the expense of the adjacent $60 \mathrm{~s}$ and $70 \mathrm{~s}$ helices (Figure 2). These helices, the $\beta$-neck, and the 40s $\Omega$ loop together account for $36 \%$ of the residues, consistent with the extent of $\beta$-sheet formation. The proposed sequence of events is supported by the sharper transition and lower temperature for the loss of turns than of helix $\left(45^{\circ}\right.$ vs $60^{\circ} \mathrm{C}$ - Figure 1 ). The $\beta$-sheet profile is broad, and covers both the turn and helix transition temperatures.

A connection to function can be seen in the visible RR spectra (Figure 3), which contain markers of the heme ligation state. ${ }^{15}$ At low temperature, the bands are characteristic of 6 -coordinate low-spin (6cLS) heme, but 6-coordinate high-spin (6cHS) heme bands grow in as the temperature rises, as does a small contribution from 5-coordinate high-spin (5cHS) heme. We infer that the Met80 ligand, which is known to be labile at low pH (we find that the $695 \mathrm{~nm}$ absorption band, which is diagnostic of Met ligation, has half the native protein intensity at $\mathrm{pH}$ 3 at $20^{\circ} \mathrm{C}$ ), is replaced by a water ligand ${ }^{16}$ producing a temperature dependent $6 \mathrm{cLS} / 6 \mathrm{cHS}$ mixture; 17 the water is partially lost at high temperature ( $5 \mathrm{cHS})$. The temperature dependence of the deconvoluted bands (Figure 3 inset) reveals the same $\mathrm{T}_{\mathrm{m}}, 54^{\circ} \mathrm{C}$, for the LS/HS conversion as for $\beta$-sheet formation (Figure 1). The heme propionate substituents form $\mathrm{H}$-bonds with the backbone CO of Thr49 and the indole sidechain of Trp59; both residues are on the 37-61 foldon (Figure 2). We suggest that the switch to $\beta$-sheet displaces the heme, via these H-bonds, augmenting the Met80-Fe bond rupture. 
Loss of the Met80 ligand provides access to exogenous ligands, including hydrogen peroxide, which can easily displace the weakly bound water molecule. We found that peroxidase activity is indeed induced, with a $\mathrm{T}_{\mathrm{m}}$ near $54^{\circ} \mathrm{C}$, when cyt $\mathrm{c}$ is heated at $\mathrm{pH} 3$ (Figure 4). Peroxidase activity is negligible at $\mathrm{pH} 7$, regardless of temperature. Thus peroxidase activity and $\beta$-sheet formation are directly correlated.

It is possible that cardiolipin binding to cyt $\mathrm{c}$ induces a similar conformational switch to the $\beta$-sheet structure, ${ }^{18}$ resulting in heme exposure and cardiolipin peroxidation, as part of the apoptotic mechanism. The trigger for this switch could be H-bonding of the anionic cardiolipin head group to His 26 , whose protonation is likely responsible for the $\mathrm{pH} 3$ response at elevated temperature.

\section{Supplementary Material}

Refer to Web version on PubMed Central for supplementary material.

\section{Acknowledgment}

This work was supported by NIH grant GM 25158. (to T.G.S.) and GM 036298 (to J. T. G.).

\section{REFERENCES}

1. Green DR, Reed JC. Science 1998;281:1309. [PubMed: 9721092]

2. Jemmerson R, Liu J, Hausauer D, Lam KP, Mondino A, Nelson RD. Biochemistry 1999;38:3599. [PubMed: 10090746]

3. Belikova NA, Vladimirov YA, Osipov AN, Kapralov AA, Tyurin VA, Potapovich MV, Basova LV, Peterson J, Kurnikov IV, Kagan VE. Biochemistry 2006;45:4998. [PubMed: 16605268]

4. (a) Nantes IL, Zucchi MR, Nascimento OR, Faljoni-Alario A. J. Biol. Chem 2001;276:153. [PubMed: 11027687] (b) Oellerich S, Lecomte S, Paternostre M, Heimburg T, Hildebrandt P. J. Phys. Chem. B 2004;108:3871.

5. (a) Spooner PJR, Watts A. Biochemistry 1991;30:3871. [PubMed: 1850290] (b) Spooner PJR, Watts A. Biochemistry 1991;30:3880. [PubMed: 1850291]

6. Sinibaldi F, Mei G, Polticelli F, Piro MC, Howes BD, Smulevich G, Santucci R, Ascoli F, Fiorucci L. Protein Sci 2005;14:1049. [PubMed: 15741329]

7. (a) Balakrishnan G, Hu Y, Nielsen SB, Spiro TG. Appl. Spectrosc 2005;59:776. [PubMed: 16053544]

(b) Huang CY, Balakrishnan G, Spiro TG. J. Raman Spectrosc 2006;37:277.

8. Bushnell GW, Louie GV, Brayer GD. J. Mol. Biol 1990;214:585. [PubMed: 2166170]

9. Dong AC, Randolph TW, Carpenter JF. J. Biol. Chem 2000;275:27689. [PubMed: 10871628]

10. (a) Nawrocki JP, Chu RA, Pannell LK, Bai YW. J. Mol. Biol 1999;293:991. [PubMed: 10547279]

(b) Segel DJ, Eliezer D, Uversky V, Fink AL, Hodgson KO, Doniach S. Biochemistry 1999;38:15352. [PubMed: 10563821]

11. (a) Balakrishnan G, Hu Y, Spiro TG. Appl. Spectrosc 2006;60:347. [PubMed: 16613628] (b) Huang CY, Balakrishnan G, Spiro TG. Biochemistry 2005;44:15734. [PubMed: 16313176] (c) JiJi RD,

Balakrishnan G, Hu Y, Spiro TG. Biochemistry 2006;45:34. [PubMed: 16388578]

12. Leszczynski JF, Rose GD. Science 1986;234:849. [PubMed: 3775366]

13. (a) Krishna MMG, Lin Y, Rumbley JN, Englander SW. J. Mol. Biol 2003;331:29. [PubMed: 12875833] (b) Krishna MMG, Maity H, Rumbley JN, Lin Y, Englander SW. J. Mol. Biol 2006;359:1410. [PubMed: 16690080]

14. Sinibaldi F, Howes BD, Piro MC, Caroppi P, Mei G, Ascoli F, Smulevich G, Santucci R. J. Biol. Inorg. Chem 2006;11:52. [PubMed: 16320010]

15. Spiro, TG.; Li, XY. Resonance Raman Spectroscopy of Metalloporphyrins. In: Spiro, TG., editor. Biological Applications of Raman Spectroscopy. Vol. 3. New York: Wiley \& Sons, Inc.; 1988. p. $1-37$. 
16. Takahashi S, Yeh SR, Das TK, Chan CK, Gottfried DS, Rousseau DL. Nat. Str. Biol 1997;4:44.

17. (a) Jordan T, Eads JC, Spiro TG. Protein Sci 1995;4:716. [PubMed: 7613469] (b) Oellerich S, Wackerbarth H, Hildebrandt P. J. Phys. Chem. B 2002;106:6566.

18. Mixing cyt $\mathrm{c}$ with anionic lipids induces only small changes in the amide I' IR band, but large temperature-dependent enhancement of amide H/D exchange rates. (a) Muga A, Mantsch HH, Surewicz WK. Biochemistry 1991;30:7219. [PubMed: 1649625] (b) Heimburg T, Marsh D. Biophys. J 1993;65:2408. [PubMed: 8312479] 


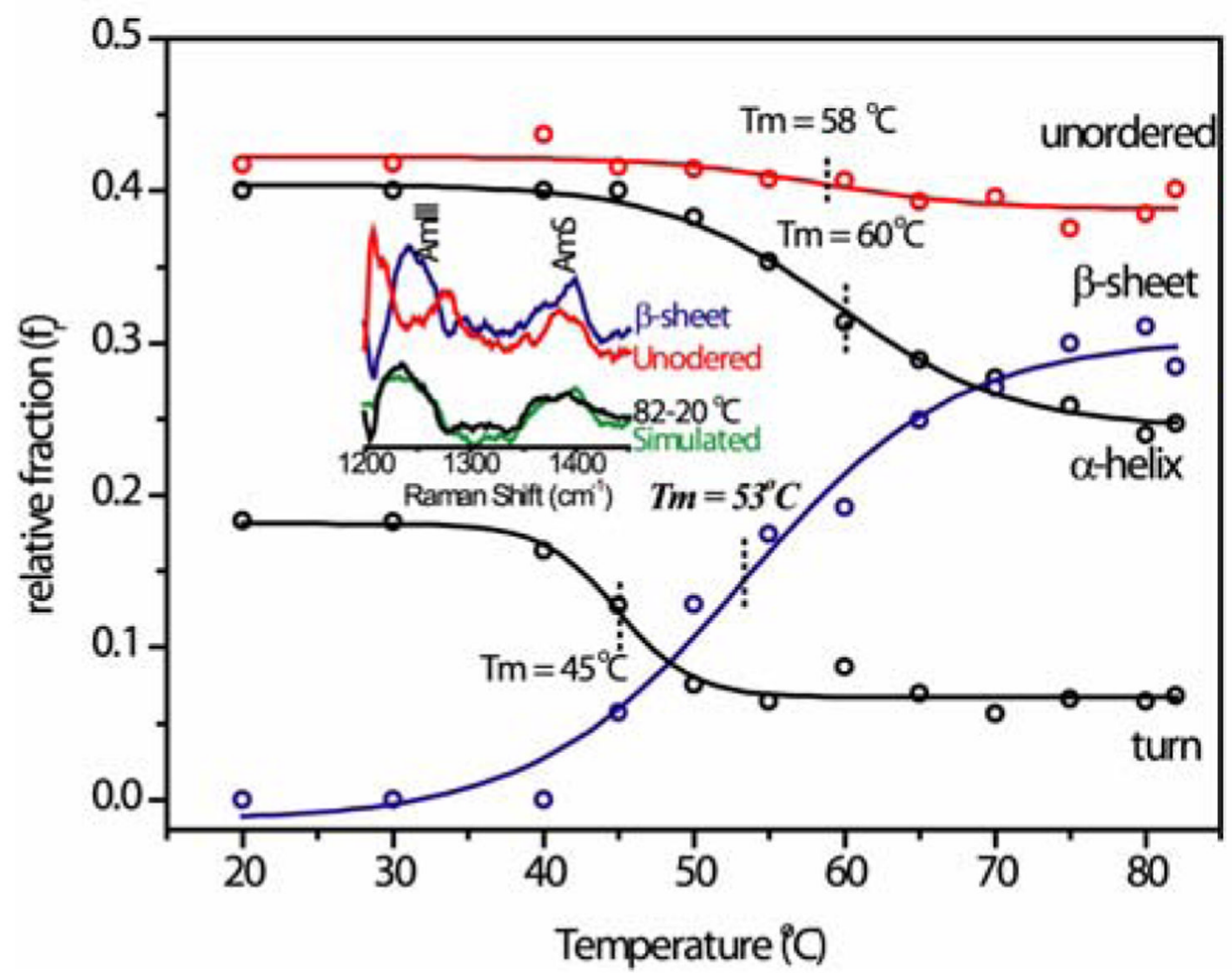

Figure 1.

$\mathrm{Fe}^{\mathrm{III}}$ cyt c secondary structure contributions at $\mathrm{pH} 3(50 \mu \mathrm{M})$ extracted from $197 \mathrm{~nm}$-excited UVRR spectra. The inset shows the distinctive spectral profiles ${ }^{7 b}$ for $\beta$-sheet and unordered structure in the amide III and S region, and the quality of data fitting via simulation of the $82-20^{\circ} \mathrm{C}$ difference spectrum. 


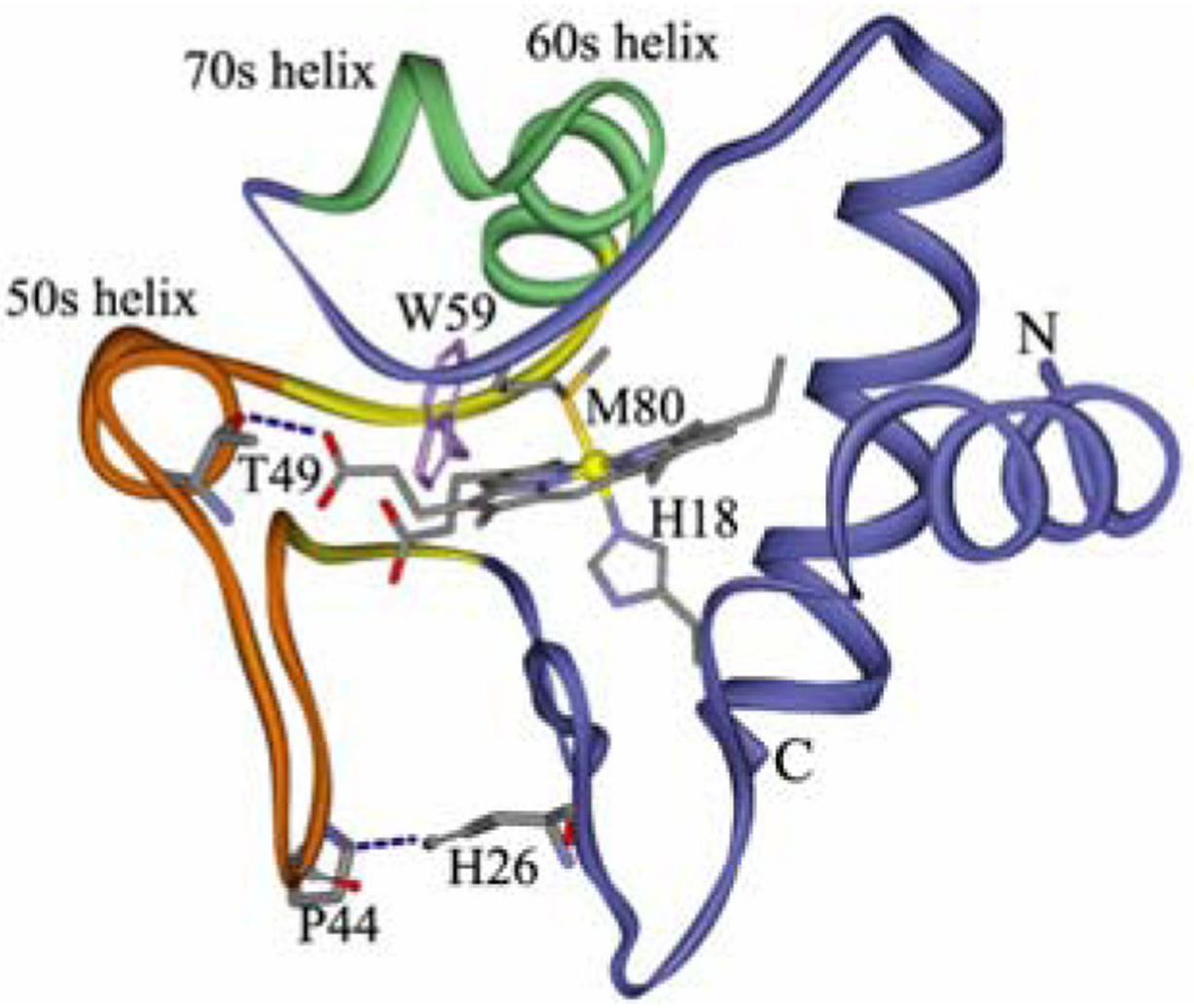

Figure 2.

Ribbon diagram of cyt c, highlighting the 40 s $\Omega$ loop (orange) and the 37-61 foldon with its $37-39 / 58-61 \beta$-sheet neck (yellow). This $\beta$-sheet segment is suggested to extend into the $40 \mathrm{~s}$ $\Omega$ loop when the latter is destabilized by disruption of the H26...P44 H-bond via protonation of $\mathrm{H} 26$. The conformational switch is proposed to displace the heme via the propionate $\mathrm{H}$ bonds, inducing Met80-Fe bond rupture. 


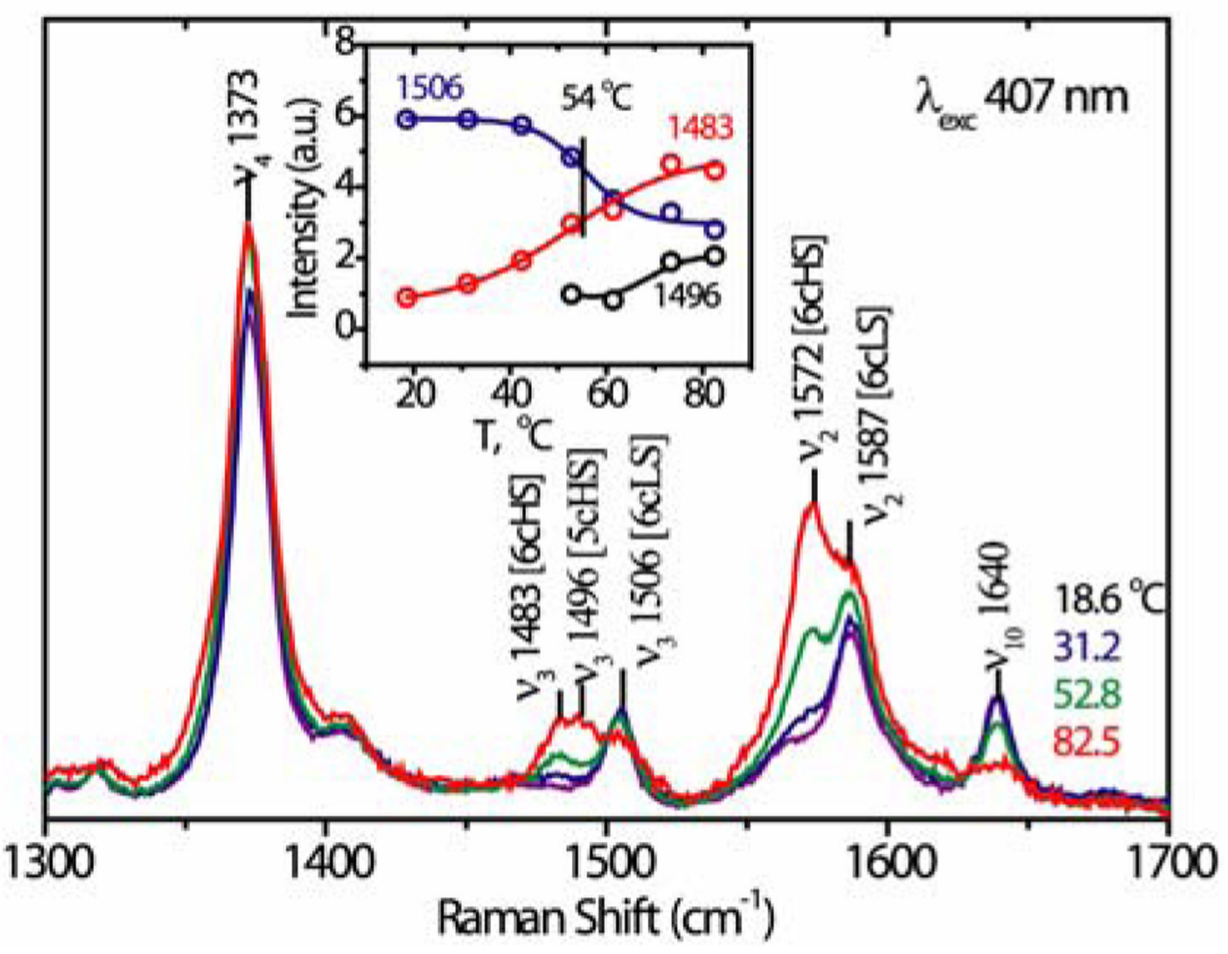

Figure 3.

The replacement of low-spin by high-spin heme in cyt c $(50 \mu \mathrm{M})$ at pH 3 is signaled by 407 nm-excited porphyrin RR bands. ${ }^{15}$ The deconvoluted $v_{3}$ band heights reveal the same transition temperature as for $\beta$-sheet formation; at higher temperature, a small fraction of 5coordinate heme appears $\left(1496 \mathrm{~cm}^{-1}\right)$. 


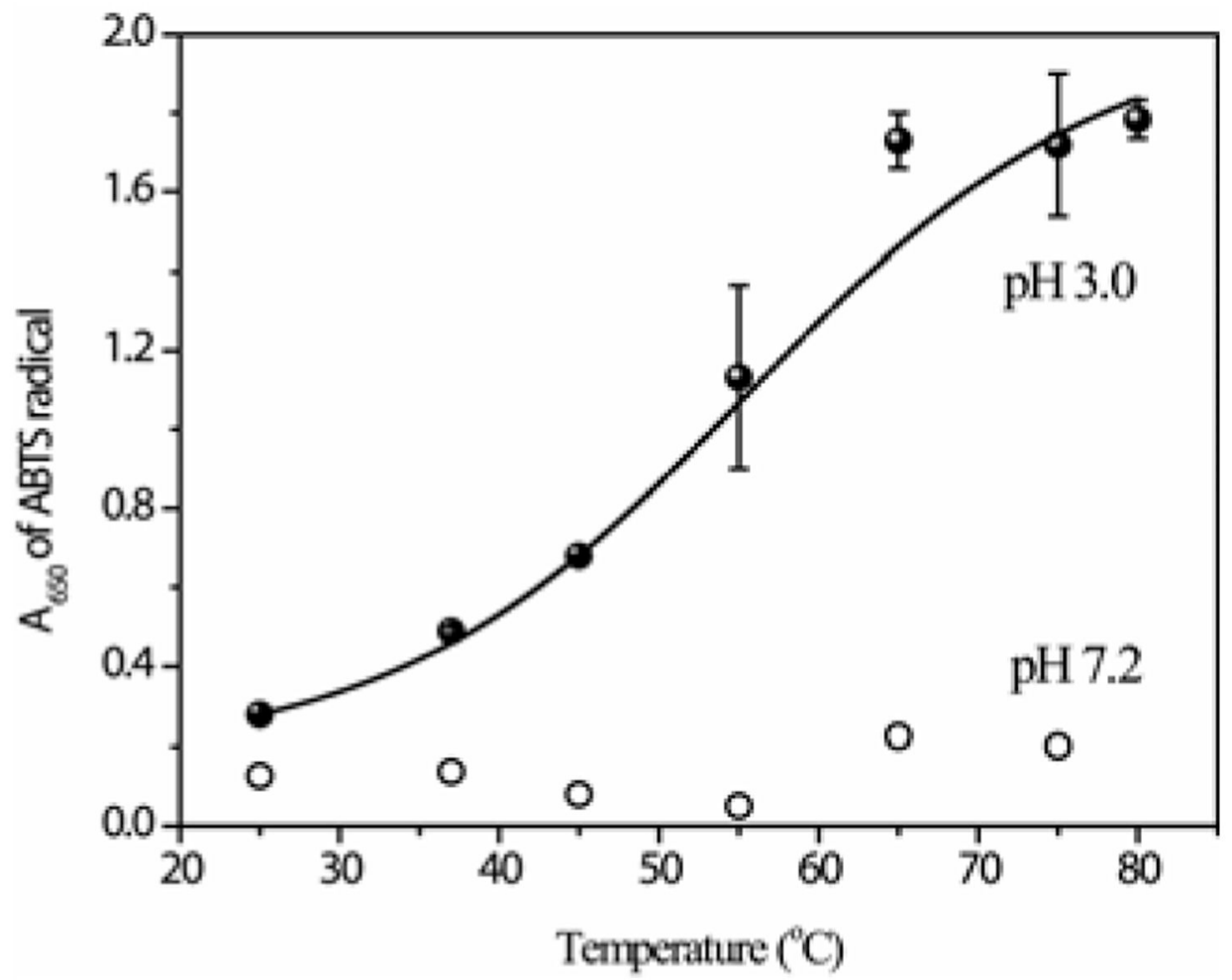

Figure 4.

Peroxidase activity (measured spectrophotometrically with ABTS as substrate - see supporting info, S4) of cyt c $(0.5 \mu \mathrm{M})$ is induced at $\mathrm{pH} 3$ (but not at $\mathrm{pH} 7)$, with the same transition temperature as $\beta$-sheet formation. 